\section{Opinión}

REV EXP MED

$2021 ; 7(2)$.

Abril - Junio

\title{
Convicciones éticas en los profesionales de enfermería: Una reflexión hacia el autocuidado
}

\author{
Ethical convictions in nursing professionals: A reflection on self-care
}

\author{
Adita Rocio Medina-Quispe 1,a
}

\begin{abstract}
Con la actualización de la tecnología y el surgimiento de nuevas tendencias los enfermeros no son ajenos a sentir cambios profundos en las organizaciones. Cada día desde su sitial desarrollan un sin número de actividades ligadas a su quehacer profesional. Ellos, como miembros del equipo de salud en las instituciones, día a día enfrentan falencias del sistema de salud como problemas de presupuesto, brecha de recursos humanos, etc.; lo genera que como usuarios internos vivencien las deficiencias y sufran las consecuencias de lo que estas generan directa e indirectamente.
\end{abstract}

Así, desde la revolución de Florence Nightingale hasta la actualidad; a medida que la enfermería evoluciona se evidencia el avance más notorio con el surgimiento de la enfermería en práctica avanzada ligado a las convicciones éticas. Este progreso permite también evidenciar que los fundamentos filosóficos de la enfermería actual difieren a los de otras profesiones, si se tiene en cuenta que las teorías de enfermería, expresan claramente que la enfermería se relaciona con las personas, con la dignidad del ser humano en forma integral, para lo cual es fundamental el concepto de "holismo" tanto en la salud como en las prácticas y en el cuidado (1).

Hablar de convicciones, implica invocar a la idea o creencia de actos que se rigen por la ética; en donde los enfermeros tienen el sentido trascendental en el cuidado de otro ser humano con acciones donde prima la defensa a la vida como derecho inalienable a pesar del contexto que le rodea. En cierto modo al contar con libertad en las convicciones éticas aunadas a la responsabilidad de las mismas marcan un sendero de sentido al bien común; ¿qué pasaría si se deja de actuar con la responsabilidad requerida para cumplir las funciones asignadas dejando de lado la conciencia de cada individuo? Una institución o un grupo de personas que dirigen una entidad, no pueden imponer una ética oficial a sus colaboradores. En otras palabras, no puede expresar qué convicciones son éticas y cuáles no.

Un auténtico profesional de enfermería formado en principios y valores no califica ni descalifica las convicciones o creencias de sus colegas. Respeta absolutamente el actuar de la conciencia. El código de ética y deontología del colegio de enfermeros del Perú refiere en su apartado que, la conducta ética es el comportamiento que evidencia un sistema de valores y principios ético-morales en el quehacer diario de la enfermera(o), asimismo se refleja en las relaciones humanas que conserva con la persona y la sociedad (2).

De igual importancia, resulta hacer hincapié que, para conseguir el desarrollo de una personalidad ética integral es importante abordar específicamente contenidos propios, apoyados en el desarrollo de una conciencia moral autónoma. En la construcción de una personalidad ética sólida en donde se abarcan tres niveles diferenciados que, al interactuar de modo permanente, conducen a la formación real de la persona. Estos tres niveles se orientan a: El desarrollo de un fuerte "sentido de vida", lo que implica la capacidad de dar una respuesta autónoma a la pregunta fundamental de la vida, seguidamente, el desarrollo de un "proyecto de vida" concreto y realizable. Esto implica un intento consciente y deliberado de alcanzar coherencia personal entre los propios ideales y la escala de valores. Por último, el desarrollo de una "estructura ética personal" capaz de realizar y sostener los contenidos éticos de la propia vida (1). Estas tres estructuras están estrechamente concatenadas una con la otra de manera que es difícil desvincularlas.

\footnotetext{
1. Unidad de Cuidados intensivos, Hospital Regional Lambayeque, Chiclayo, Perú

a. Licenciada en enfermería, especialista en cuidados críticos y emergencia, maestra en enfermería
} 
El Artículo 44 del código de ética del colegio de enfermeros del Perú, refiere que el profesional de enfermería debe reconocer el valor de sus colegas como personas y como profesionales, propiciando su desarrollo en el campo científico, sociocultural, personal y ético ${ }^{(2)}$; es decir, propiciar espacios para el desarrollo personal y profesional tal como lo afirma la destacada Ernestine Wiedenbach quien centra su teoría en las interacciones entre la enfermera y el paciente. En este caso, la colega se empatiza y se transforma en paciente a quien define como cualquier individuo que recibe ayuda de cualquier tipo, bien sean cuidados, instrucciones o avisos procedentes de un profesional de la salud, por lo tanto, para ser un paciente no se necesita estar enfermo". Considera que tanto la enfermera como el paciente son seres humanos, dotados de potenciales únicos, que luchan por la autodeterminación y que como tales, actúan, piensan y sienten. Plantea, además, que la enfermera, debe aprender a disciplinar sus pensamientos y sentimientos ${ }^{(3)}$.

Por otro lado, el reflexionar acerca de las convicciones éticas de los enfermeros, conduce a poner énfasis en principios y valores, que guían la práctica de la enfermería. Más allá del trato al paciente o usuario de los servicios de salud, se encuentra el cuidado que brinda el profesional de enfermería hacia un empoderamiento real de la profesión. Un reto importante para el profesional de enfermería es progresar en el logro de eminentes horizontes de la profesión, obtener autonomía con competencia profesional, publicar y participar activamente en asociaciones científicas y sociedades donde les permita compartir el conocimiento especializado ${ }^{(4)}$. Al tomar decisiones éticas congruentes con el ser y el hacer, la enfermera siempre se pregunta ¿están a favor de la persona, de su desarrollo, de sus derechos, de su calidad de vida y del bien común? En un solo objetivo para que el producto de la toma de decisiones muestre resultados concretos, medibles en mejora de los servicios de enfermería.

Aparte, resulta trascendente fortalecer el trabajo en equipo. Descubrir que, en la diversidad de criterios y puntos de vista, se confluye para mejorar de manera coordinada con liderazgo, con reconocimiento de los propios límites, frente a la complejidad de que como personas somos seres unitarios e irrepetibles 3 . Acciones que enmarcan un paradigma transformador y de esta manera los enfermeros se sientan motivados y reconocidos; requisito fundamental en el cuidar del cuidador; razón misma de una gestión basada en convicciones éticas propias de la misma naturaleza humana como es la profesión de enfermería.

Por lo tanto, las convicciones éticas en los profesionales de enfermería emergen desde la búsqueda perfectible en la práctica avanzada o especializada; en un contexto de formación constante en la profesión y en el amor que se profesa al cuidar al ser humano desde la apertura al conocimiento con bases filosóficas, antropológicas y epistemológicas del cuidado enfermero. También, buscando el sentido de vida, la razón del ser existencial valorando su propio ser el cual se renueva al trascender en la vida de quienes cuida con amor, respetando las apreciaciones del equipo de trabajo, de los seres cuidados, buscando cuidar el don supremo que es la vida más allá del temor presente en contextos por la pandemia.

Conflicto de interés: Ninguno

\section{REFERENCIAS BIBLIOGRÁFICAS}

1. Restrepo L. La enseñanza ética en enfermería. Aquichan [internet]. 2001 [citado el 26 de junio del 2021]; 1(1): pp.35-36. Disponible en: https:// aquichan.unisabana.edu.co/index.php/aquichan/article/view/11/19.

2. Colegio de enfermeros del Perú. Código de ética y deontología, 2009 [internet]. Lima: CEP;2009 [Citado el 26 de junio del 2021]. Disponible en: https://www.cep.org.pe/download/codigo_etica_deontologia.pdf.

3. Marriner T, Raile M. Modelos y Teorías de Enfermería. Madrid: Elsevier; 2015

4. Luengo-Martínez C, Paravic-Klijn T, Burgos-Moreno M. Profesionalismo en enfermería: una revisión de la literatura. Enfermería Universitaria. 2017;14(2):131-142. doi: 10.1016/j.reu.2017.02.001

5. Feito L. Ética y enfermería. Madrid: San Pablo; 2009. 